\title{
State of Food vs Income-Expenditure Gap in Developing World with a Focus on Iran
}

\author{
Mohammad Taghi Sheykhi* \\ Professor Emeritus of Sociology, Alzahra University, Tehran, Iran
}

*Corresponding author: Mohammad Taghi Sheykhi, Professor Emeritus of Sociology, Alzahra University, Tehran, Iran.

\author{
Received Date: July 15, 2019 \\ Published Date: July 31, 2019
}

\begin{abstract}
The paper explores how insecurity in food accessibility is largely emerging especially within the younger generations who are unemployed, or underemployed. Their income shortage usually deprive them of the quantity and quality of the food that they need. Such a situation causes increasing vulnerabilities for them. Psychologically speaking, it contributes to overweight and obesity among many. Overeating often happens within the poor-leading to various issues. Because of the aforementioned situation, culture of street food supply has emerged in increasing number of developing countries to respond the demand of the increasing low-income people. Shortage of income not only creates food issues, but delays marriage and formation of family in developing countries. This situation that leads to stigmas and lots of social problems in many developing countries; eventually affect birth rates among younger generations. Jobs and earnings largely affect quality of life including access to healthy food and housing. Unfortunately, food accessibility will be more serious in the decades to come with special reference to the developing world, as among other barometers, more people will be residing in urban areas which are more consuming sectors.
\end{abstract}

Keywords: Food accessibility; Street food; Income-Expenditure gap; Low-income youth; Lifestyle

\section{Introduction}

The survey intends to investigate the financial status of the youth, i.e. age groups 18-29 of both genders in developing world. The survey aims to serve for the socio-financial empowerment of youth and will eventually contribute to the implementation and realization of the youth who need effective and influencing policies to improve their quality of life. Based on Iran's national census in 2011, approximately youth include $33 \%$ or 25 million of the total population of the country. The demographic profile of the increasing youth at the age of employability and income indicates that a large number of the educated and skilled youth do not enjoy adequate financial and intellectual opportunities available to their counterparts in developed and newly emerging economies. However, social and economic hazards and disparities have their effects on the quality of life of the young men and women of Iran. Such a situation makes the youth of both genders very vulnerable. High and rising figures of unemployment especially within the youth have contributed to serious concerns. Sociologically speaking such issues will cause long-term challenges if not addressed in time and in place.

Lack of social and financial infrastructures being faced by the younger generations is principally because of the inadequacy of budgeting knowledge and other shortcomings to build a secure financial future, younger generations are needed to harmonize their income and expenditures, but it more often does not happen so. As a result, increasing number of male and female youth in Iran at working age do not earn any regular monthly income, and inevitably depend on the income of their parents. At the time of being, younger people are at the risk of facing emerging controversies caused by socio-economic change, new modes of life and changing lifestyles. While all of them need stronger financial sources, large numbers of youth cannot attain it, and consequently remain destitute and disappointed. Such deprived people without jobs and income cannot set up their marital life, and that has led to vulnerabilities including social and cultural issues within younger generations in almost all parts of the country. Postponement of marriage largely causes decreasing rate of fertility, and for some even infertility. In long term, the scenario contributes to economic vulnerabilities.

Adequate investing in young generations change their lives and transform them toward further and healthy development. Such a movement leads to further socio-economic progress. Likewise, prosperity of the youth leads to their dynamism affecting the 
mainstream of economic cycle, and the mainstream will continue. Creation of a healthy environment eventually leads to improvement of lives and rights of the young generation. The youth could access better and constructive education, information services and the like in this way. That would lastly pay the youth as well as the society. However, the socio-economic process would be influenced, and the youth would also realize their potentialities as the agents for economic and social change. Therefore, improving the profile of the youth in Iran through income and right jobs, would culminate in positive returns for them as well as for the society. The created motivation will uplift the social responsibility of the youth as well as their improved quality of life.

However, vulnerabilities of the youth could be prevented through promoting the financial capabilities. That would also control the emergence of other deprivations as well. Access to regular income to meet the youths' increasing needs would be possible mainly through decentralization of planning and investment. Notwithstanding, creating a balance between income and expenditure of the youth will culminate in their improved health status, their quality of life, and their social network as a whole. Young generation highly aspires to have paid jobs, but very few succeed, and many of those not succeeded try to get engaged in open and free occupations. While it is believed that money cannot purchase happiness, but it can bring about higher living standard, greater well-being, and eliminate economic and social challenges. However, youths' net-adjusted disposable income is the amount of money that a young woman or man earns per month or year after transfers and taxes. The current article refers to the amount of money within the reach of a young woman or man to spend on food, goods and services. Therefore, holding an occupation includes several remarkable benefits as a source of income, reaching one's aspirations, and improving competencies, skills etc. within the youth.

\section{Methodology}

The research techniques used in the present research to yield the intended social data is based on a mixed-method strategy of investigation. While the main technique of study in the present research is administering questionnaires, the researcher also used interview method as per need. In addition, documents and books were also used as major sources of inquiries. In the theoretical section, the author has referred to relevant theories, approaches and literature reviews. In completing the research, 555 samples of both genders were consulted to produce a reliable and valid work. The research is based on the main hypothesis that: "reasonable permanent income determines the propensity to consume". However, the researcher used both the quantitative and qualitative methods to reflect the financial conditions of the youth in terms of income and expenditure in a changing urban society.

\section{Theoretical Perspectives}

Youth unemployment that leads to income problems, is often seen in terms of moral crisis. It is in practice, when jobs are extremely hard to obtain. However, more than 40 percent of the world's unemployed are youth United Nations 2002 [1].
In most parts of the world, youth unemployment exceeds that among older people O'Higgins [2]. However, many young people are underemployed, meaning that they have insufficient work to keep them fully occupied which means that they earn inadequate income to be able to meet their basic needs. They may also usually have poor-quality employment in informal sector. There are many views why unemployment is high within the youth. Some stem from population, but in addition, there are many more reasons responsible for the problem O'Higgins [2]. Youth unemployment rates are much in conjunction with adult unemployment as well as the conditions of economic growth. However, youth labor force cannot compete for occupations that require skills at high levels and maturity as far as experience is concerned. Therefore, such criteria are valued and counted for in employment occasions.

Similarly, youth unemployment/income issue is much subject to economic decline. For example, labor market has structurally declined in Central Asia, and there are uncertain prospects to school leavers Falkingham [3]. If we go back to Soviet era, in a country like Kazakhstan, there were a lot of opportunities available to youth who left schools and universities, especially for those with parents of high social standing Rigi [4].

As far as the developing countries are concerned, unemployment is concentrated among selected social groups of the youth; especially the poor. However, the gender distribution of unemployment is not very clear among the youth. In this regard, women usually have lower chances as compared with men. For example, in Jamaica and Iran where educational attainment is higher among females than males, women are more subject to unemployment O'Higgins [2]. In societies where education gives self-respect to the youth such as India, they are not willing to work as laborers Jeffrey et al. [5]. As a result, youth unemployment can lead to marginalization, exclusion, frustration, low self-esteem and sometimes to acts that create burdens on society (United Nations 2002). However socioeconomic change has contributed to a fresh occasions/opportunity that enable youth of both genders to be selective in choosing their employment Kelly [6].

The state of having sufficient independent income to live on, is an important indicator of youth independent lives, and without which challenges will emerge Cummuta [7]. However, if the youth can generate income that is greater than their expenditures, then they would feel comfortable and happy. To harmonize income with expenditure, and to prevent bankruptcy, simple living is advised, or other strategies to reduce expenses. Based on passive source of income or unearned income such as rentals, or interest from a bank account etc., if stopped, income and expenditure do not cope with each other, and thus challenges will emerge Retrived [8].

Strain theories also predict a link between economic deprivation and youth violence Merton [9]. By that is meant; absence of income, or an unbalanced income- expenditure relationship is very likely to lead to rebellion and other social vulnerabilities. Similarly, based on economic theories of crime, poverty lay the ground, while inequality servers to further exacerbate the situation $[10,11,12]$. 
Income and employment theory represent the level of expenditure by the people in the course of time. Keynes also offered new thinking on income and employment theory with the publication of General Theory of Employment, Interest and Money (1936). Based on this theory, transactions are two-sided, and that is: one person's income is another person's expenditure. Therefore, fall in incomes further reduces consumer demand, and it eventually reduces the rate of savings Encyclopedia Britannica [13].

Consumption function as a response to income creates economic transactions, economic prosperity, and a state of tranquility for the youth. Consumption is based on current income and ignores potential future income D' Orlando [14]. Consumption is also relative to production. Therefore, consumption or somehow expenditure has to be analyzed in the context of a person's production/income Mincer [15]. As developing countries are copying the consumption patterns and modes of the developed economies, that will create shortage that earth could not fulfill. Therefore, affordable policies and strategies need to be adopted and practiced.

Modernization theory has multi-dimensionally affected the youth with special reference to those of the developing world through education, industrialization, urbanization etc. Rostow [16]. This process is rapidly continuing in new dimensions such as the electronics and communications. Mass education is assessed as both a requirement for, and an indicator of modernity Inkeles and Smith [17]. Education as a platform has largely transformed the value system of the youth, their socio-economic expectations, and their lifestyles. Such circumstances motivate the youth to have access to adequate incomes leading to new expenditures in terms of goods and services. Human capital theory which is known as a drive for economic growth originates from modernization theory. On the country, lack of skills and education among the young labor force in the Third World countries is believed to hold back productivity. Therefore, children are a resource to be invested in UNICEF [18]. As a result, both education and technologies such as schools and immunization contribute and improve the health of the future workforce.

In modern times, the youth expect formal employment which is not always fulfilled. Under such circumstances the youths' income and expenditure do not remain balanced. It is to be notified that modernization led to inspirations having great impacts on youth such as schooling and immunization. For example, investment in industrialization was followed by rapid urbanization which gradually led to new expectations, new ways of life, more and new foods to take etc.

\section{Socialism and dependency theory}

Some of the countries that got independence from 1950 onwards, partly rejected the Western style of development, and instead chose the policies/ideologies based on Marxist thoughts and institutions. These countries are ranked as China, Chile, Cuba and Ethiopia. Though it was implemented differently from nation to nation, in this process, land, mineral resources and industries were nationalized, and foreign trade and investment brought under state control, followed by rigid price controls Kilmister [19]. The purpose of such development was to benefit the lower classes, and not just the owners of capital. In that, youth employment and income were assured and fulfilled according to the governing standards. Based on Marxian thought and dependency theory, social investment on children and youth is highly emphasized and desirable. In that, children are more considered legitimate subjects of government intervention. They are considered as a nation's future.

\section{Youth and housing}

Human beings as top social creatures are extensively associated with social networks, and the stronger it is, they have higher chance of access to employment opportunities, different services, and more other opportunities. On the other hand, shortage of social ties through networks may lead to restricted socio-economic occasions and connections, and lastly, the emergence of isolation. As a result, the new conditions lead to failure of one's wants and aspirations. Training and education as important and necessary elements highly help in the development of youths, and their socio-economic wellbeing. The factors mentioned have leading and determining impact on quality of life of the youths, their access to food etc.

Housing needs of human beings could also be facilitated and solved through better networks. Moreover, economic and social conditions of the country also play a determining role to meet such a basic requirement. In general, poverty also as a widespread global issue with various dimensions could be solved as a country specific phenomenon Uberoi [20]. Therefore, youths' resources and productivity as an effective strategy highly plays role to develop the youths and decrease their poverty. To attain the aim, the programs of higher income generation and job opportunities need to be prioritized.

Generally, females have low labor force participation chance, and that contributes to shortage of income within them leading to eventually delay in marriage. Therefore, the scenario makes young females vulnerable in different respects. Nonetheless there are high hopes and prospects for more female participation and employment in urban areas with special reference to universityeducated females under the recent landmark deal with world powers and the socio-political developments in Iran.

Humans as social creatures are highly dependent on social network, and if stronger, they can have better access to jobs, services and various opportunities. On the contrary, lack of poor social network may lead to limited economic opportunities, and ultimately the appearance of isolation. Similarly, the emerging conditions could result in failure of personal aspirations. Similarly, education and training are two elements necessary for the youth development and economic well-being. The above-mentioned factors have a direct impact on the quality of youth housing.

The importance of housing needs no emphasis; it is one of our primary needs of life (Rao,2001). Housing issues in Iran are associated much to social and economic conditions of the country. Poverty being a multi-dimensional problem, and a major challenge 
all over the globe, its solutions are country specific Uberoi [20]. Therefore, an effective strategy is needed to tackle the problems of development and poverty beginning with economic conditions of the youth, their resources and productivity. To reach the objective, youth employment and income- generating programs need to be put on the agenda.

\section{Youth and change}

Youth are described as agents of change, or so to say, the "barometer of social change". They are subject to any changes at world level and respond most effectively to them. However, the generational divide should not become a social divide. The new society must seek to prevent exclusion, integrate the young and the old, and the rich and the poor (Tiong:2004). Therefore, young people are expected to establish themselves in a new social context, and deal with any vulnerability, the new world provides new possibilities as well as threats. However, one of the challenges as recognized, being faced by the youth in modern times is the income of the youth in countries like Iran with very young population structure with the median age of 28.3 in 2015 (Consus:2011). Iran's human development index (HDI) has largely changed in the past recent decades. In that, greater number of youths have obtained university degrees at graduate and post graduate levels, but income and employment opportunities have not developed as such. The gap create, has resulted in income and expenditure problems within the youth.

\section{State of Food}

Food insecurity is largely because of the gap between income and expenditure. That is to say, chronic food deprivation, which was 804 million in 2016, increased to 821 million for the poor people in 2017 (Retrieved, 2019). Similarly, the share of undernourished people in the world reached 10.9 percent in 2017. Adverse climate events, economic slowdowns and other factors have contributed to the existing deteriorating situation, and most probably the situation will worsen in the years to come. It is widely appearing in South America and most regions of Africa.

Although it might appear to be a paradox, food insecurity can also contribute to obesity and overweight. As nutrition and fresh foods often tend to be expensive, thus household resources for food become scarce, and as a result, people choose less expensive foods that are often high in calories and low in nutrients. Not having adequate access to food often causes feelings of anxiety, stress and depression--all psychological effects which in turn can lead to behaviors that increase the risk of obesity and overweight. These include patterns of overeating when food is available, or choosing low-cost, energy-dense foods rich in fat, sugar and salt FAO [21].

Street food supply as an alternative helps many people, especially the low-income youth and households not only in the developing world, but it has entered the developed countries too. Street food vendors supply the customers with inexpensive prices. Such food services are fast increasing in clean and modern ways in a large number of developing countries; fast foods, Mcdonald's and the like are some of the examples. Even home-cooked foods are widely supplied and sold out in countries like Iran, India etc. Street foods are low in cost compared with restaurant meals and offer an attractive alternative to home-cooked food. In spite of these similarities, street food and fast food enterprises differ in variety, environment, marketing techniques and ownership MG Africa [22].

\section{Literature Review}

As a result of population explosion, the urban areas such as Tehran in Iran are facing income and employment within the increasing youth. Like many other developing countries, Iran is also a victim of rapid increase in its urban population resulting in employment chaos. The scenario has contributed to income and expenditure challenges with special reference to the young population age group of both genders. However, the emerging phenomenon has brought about various vulnerabilities. Factors responsible for the emerging situation include numbers, density and heterogeneity of population Wirth [23]. Though in the past only young men expected occupations and income, Now-a-days young women also expect the same, and the shortage of which is a matter of concerns for them too. Therefore, this is where the challenges and complications of income and expenditure start from within the youth in Iran. Thus, if the fundamental features of urban environment are not in place, a range of urban social behavior would emerge leading to social problems caused by the shortage and imbalance of income and expenditure within the youth.

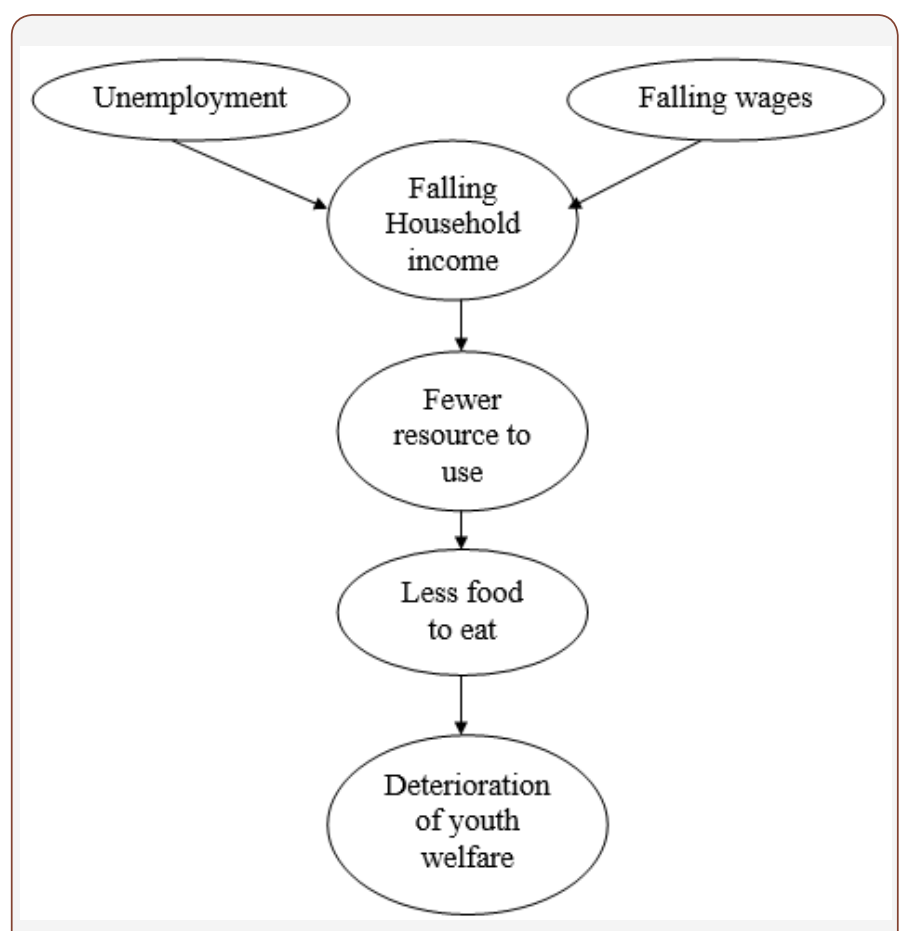

Figure 1: The impacts of structural adjustment policies on youth.

According to social mobility theory Lispset and Bendix [24], though stability of modern industrial society is maintained, yet controversies emerge due to increasing job seekers with special reference to the youth in urban areas. Another perspective denotes that technology is responsible for the nature of social relations including income, employment and housing conditions Turner [25]. However, the social interactions of the individuals are influenced by 
their economic ability. Likewise, economic sociology [26] identifies the relationship between economic conditions of the youth and their income-expenditure proportion Smelser et al. [27] (Figure 1).

\section{Income-expenditure equilibrium}

Income ladder of female respondents respectively indicates 137 $(24.7 \%)$ as having no monthly income, 38 (6.9\%) having monthly income equivalent to less than US \$150, some 29 (5.2\%) drawing monthly income equivalent to US $\$ 150$ and 199. Another group of female respondents 27 (4.8\%) people asserted to draw monthly income equivalent to US $\$ 200-249$, followed by another group of respondents 20 (3.6\%) drawing monthly income equivalent to US $\$ 250$ and 299. The sixth column of the young respondents 16 (2.9\%) people indicate drawing monthly income equivalent to US $\$ 300$ and 349, followed by another group of female respondents 19 (3.5\%) declaring their monthly income equivalent to US \$350 and 399. The ninth income group 27 (4.9\%) indicates monthly income equivalent to US $\$ 400$ and 449 , followed by 30 (5.5\%) of female respondents drawing monthly income equivalent to US \$450 and above.

Out of 211 (38\%) males, 69(12.5\%) asserted to bear monthly expenditure of equivalent to less than US $\$ 150$, followed by 54 (9.8\%) bearing monthly expenditures of US $\$ 150$ and 199 . Similarly, $30(5.4 \%)$ of the respondents reported to spend equivalent to US $\$ 200$ and 249 as their monthly expenditure, followed by 22 (4\%) respondents who asserted to spend equivalent to US \$250 and 299. Another group of young respondents 10 (1.8\%) expressed to spend equivalent to US $\$ 300$ and 349 as their monthly expenses. The sixth group of youth comprising of 12 (2.1\%) declared to spend equivalent to US $\$ 350$ and 399 as their monthly expenditure, followed by another group of $5(0.8 \%)$ of respondents who declared to spend US \$ between 400 and 449 as their monthly expenditure. The last group of $8(1.5 \%)$ of respondents declared to spend equivalent to US $\$ 450$ and above as their monthly expenditure.

\section{Discussion}

The chain of increasing automation, computerization, lowering of wages, fewer resources, and more demand for changing food habits, all have deteriorated the welfare of the youths. Incomeexpenditure relationships have negatively affected the quality of life with special reference to younger generations. This new phase of life has increased the dependency of the youths on families to more years in countries like Iran. Constant change in prices affect expenditures, leading to economic turmoil, and the economy as a whole. Consumption behavior is totally under the influence of income increase. Sociologically speaking, both boys and girls when reaching the working age, can access some income. This process is always accompanied by challenges such as late income, shortage of income, loss of income, bankruptcy--all leading to vulnerabilities within the youths, especially in many occasions because of drug addiction, and other behaviors of this type.

Housing expenditure in Tehran is the largest portion of the household budget; representing the heaviest expenditure of increasing individuals and households, especially the younger generations. The situation has currently become a challenging issue for the youths preventing them from entering a married life. Due to increasing social and family change in the country; breaking away of joint family system, the youths need independent income to establish nuclear families, and in the absence of which increasing number of social and ethical issues emerge. However, the new norms and values would not be compatible with the youths' income-expenditure gap. Since 1990s, the number of youths in Iran has been on increase far from the country's carrying capacity, and also far from the necessary infrastructures. The emerging financial gap has brought about a large number of problems and challenges, especially for the young people. Under such conditions, the lowincome cohorts are pulled towards numbers of illegal activities leading to chaos and socio-economic vulnerabilities. Under the slow-speed economic growth in Iran in the past 30years, increasing number of men and women of age groups 18-29 have remained unemployed. They are persons willing to work, but currently are not engaged in jobs.

Generally speaking, females have lower labor participation opportunities, and that leaves them on the bottom line of income within them; leading them to delayed marriages. Hence, the scenario pushes young women to vulnerabilities in different ways. Therefore, there are high hopes for further female hiring in urbanindustrial areas with particular reference to the tertiary-educated ones under the conditions of new plans in Iran. However, the gap between income and expenditure, and saving and investment disables the youths to purchase what they need; leading them to poverty. The current research investigates how incomeexpenditure relationship is influenced by age, gender, class and cultural differences. However, deprivation initiated from unmet needs, usually leads the youths towards committing crimes. Thus, income-expenditure relationships need to be carefully and positively appraised. Similarly, residential mobility, poverty, and ethnic heterogeneity caused by social disorganization affect income-expenditure relationships somehow or the other leading to dissatisfaction within the youths in many societies including Iran as well. Therefore, issues such as youths' violence, the community movement and family health may be resulted from the economic deprivation of the youths. On the contrary, some social researchers as Allen [28], and Messner [29] have reached negative relationships between poverty and lower levels of crimes. However, to bring about a logical relationship between income and expenditure for the youths, direct creation of jobs seems a pressing point an attempt to raise ways and lessen earning disparities, especially those related to gender and race Currie [30].

However, if consumption function is to maintain well, income factor must ever be ahead of that. Iran with a young population structure needs to invest more than ever before on entrepreneurship so as to create income for its youths of age (15-29), that is about $32 \%$ of the entire population Census of Population [31].

\section{Conclusion}

Equilibrium between income and expenditure contributes to the creation of a circular flow of income, and if the flow does not 
appear, increasing number of needs can't be met. Thus, welfare policies must be designed in such a way as to lead to adequate income to meet the raising expenditures according to, not only the socio-cultural values of the youths in Iran, but the youths in other societies too. Adequate and reasonable income needs to be earned by the youths so as to meet the soaring costs of housing, food, clothing, health, education, leisure, transportation etc. However, meeting the needs and welfare of the youths must be prioritized properly. Under such a desired condition, the youths are led to be highly productive and self-reliant, and if not, they will be vulnerable and deprived. If the process so continues, the whole social health will be seriously affected. As the equilibrium between income and expenditure is highly prone to State policies, therefore, applicable and reasonable policies are required to be designed and placed into practice.

As far as the youth in Iran are concerned, creation of a balance between their income and expenditure would result in their improved health status, social network, their subjective wellbeing and their quality of life as a whole. Similarly, access to an adequate source of income will enhance the youths' self-esteem and improve their skills and competencies. Though the main reason for the youth unemployment is supposed to be population increase, yet other reasons are responsible for the problem. Similarly, youths' low-income and unemployment can lead to their marginalization, exclusion, frustration and their low self-esteem. To prevent bankruptcy, harmonization of income with expenditure is suggested, and likewise simple living is advised in addition to other strategies to reduce expenses. In modern age, the youth expect formal employment that is not always fulfilled, and that is where the youths' income and expenditures do not remain balanced. It is worth mentioning that due to demographic change, and as a result increase of young population beyond the socio-economic carrying capacity, and the adequate infrastructures, emerging disequilibrium between income and expenditure is inevitable. Income-expenditure cleavage has also contributed to marriage delay in Iran in the past two decades with a focus on women __ leading to emerging problems. Similarly, as a result of modernity and new lifestyles within young women, they too expect occupations and independent income earnings as men, and the shortage of which is a matter of concerns for the educated female youth at the time being. At the end, if the consumption function is to maintain in good order, income factor, or so to say, income generation need to function ahead of expenditure to make possible access to food needs.

\section{Acknowledgement}

None.

\section{Conflict of Interest}

No conflict of interest.

\section{References}

1. United Nations (2002) World Youth Report 2003, E/CN.5/2003/4, United Nations Economic and Social Council, New York, USA.

2. O Higgins N (2011) Youth Unemployment and Employment Policy, Geneva: International Labor Office, USA.
3. Falkingham J (2000) From Security to Uncertainty. The Impact of Economic Change on Child Welfare in Central Asia, Florence: UNICEF Innocenti Research Centre, Italy.

4. Rigi J (2003) The Conditions of Post-Soviet Dispossessed Youth and Work in Almaty, Kazakhstan. Critique of Anthropology 23: 35-49.

5. Jeffrey C (2003) When Schooling Fails: Young Men, Education and Low Caste Policies in North India, Uncertain Transitions: Youth in a Comparative Perspective, Presented at the University of Edinburgh, UK.

6. Kelly PF (1999) Rethinking the Local in Labor Markets: The Consequences of Cultural Embeddedness in a Philippine Grow Zone. Singapore Journal of Tropical Geography 20: 56-75.

7. Cummuta J (2009) The Myths \& Realities of Achieving Financial Independence.

8. (2013) What is Passive Income.

9. Merton, Robert (1949) Social Theory and Social Structure, Free Press, New York, USA.

10. Becker GS (1968) Crime and Punishment: An Economic Approach. Journal of Political Economy 76: 169-217.

11. Block M, J Heineke (1975) A Labor Theoretic Analysis of the Criminal Choice, American, Economic Review 65 (3): 314-327.

12. Ehrlich I (1973) Participation in Illegitimate Activities: A Theoretical and Empirical Investigation. Journal of Political Economy 81: 521-565.

13. (2014) Encyclopedia Britannica.

14. D Orlando F, Eleonora Sanfilippo (2010) Behavioral Foundations for the Keynesian Consumption Function. Journal of Economic Psychology 31(6): 1035-1046.

15. Mincer J (1963) Market Prices, Opportunity Costs, and Income Effects. In: Christ C (Edt.), Measurement in Economics. Stanford, CA: Stanford University Press, USA.

16. Rostow WW (1960) The Stages of Economic Growth: A Non-Communist Manifesto, London: Cambridge University Press, UK.

17. Inkeles A, DH Smith (1974) Becoming Modern, London: Heinemann, UK. 18. UNICEF (1996) Fifty Years for Children.

19. Kimister A, Allen T, Thomas A (eds) (2000) Socialist Models of Development, in Poverty and Development into the $21^{\text {st }}$ Century, Oxford: Oxford University Press, Open University, USA, pp: 309-324.

20. Uberoi NK (2003) Environmental Management (P.6). New Delhi: Excel Books, India.

21. (2018) The State of Food Security and Nutrition in the World, FAO.

22. (2016) Why African Cities are Full of Street Vendors and Hawkers- and How We Can Create Better Jobs, MG, Africa.

23. Wirth, Louis., (1938) Urbanism, as a Way of Life. American Journal of Sociology 44:1-24.

24. Lipset SM, R Bendix (1959) Social Mobility in Industrial Society, Berkley, University of California Press, USA.

25. Turner BS, Abercrombie N, Hill S (2000) The Penguin.

26. Dictionary of Sociology, London: Penguin Books, UK, pp: 1-274.

27. Smelser NJ, R Swedberg (1999) Handbook of Economic Sociology, Princeton: Princeton University Press, USA.

28. Allen RC (1996) Socio-economic Conditions and Property Crime: A Comprehensive Review and Test of the Professional Literature. American Journal of Economics and Sociology 55(3): 293-308.

29. Messner SF (1982) Poverty, Inequality and the Urban Homicide Rate: Some Unexpected Findings. Criminology 20(1): 103-114.

30. Currie E (1996) Missing Pieces: Notes on Crime, Poverty and Social Policy. Critical Criminology 7(1): 37-52.

31. Census of Population and Housing of Iran (2011), Statistical Center of Iran, Iran. 